
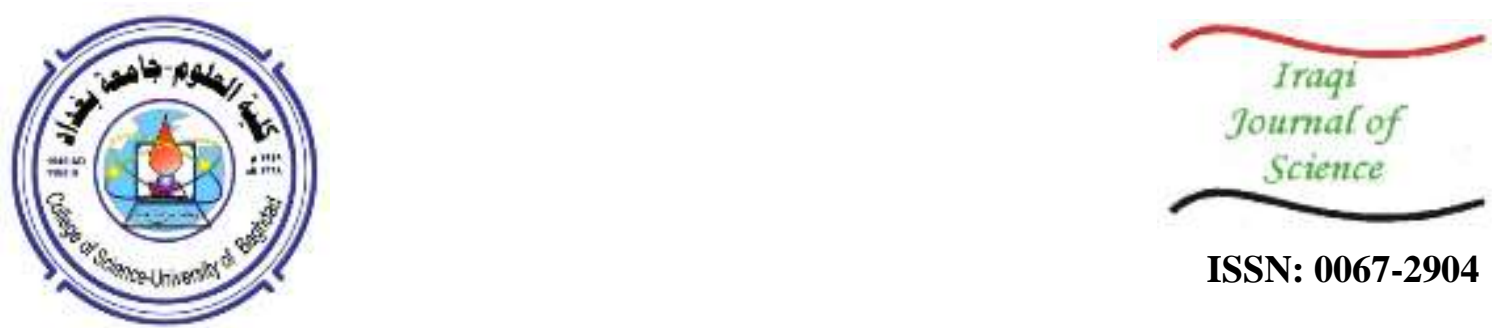

ISSN: 0067-2904

\title{
Comparative Study of Ranking Methods for Fuzzy Transportation
}

\author{
Sami Kadhem kareem Al thabhawi \\ Department of Mathematics, College of Education, University of Kufa, Kufa, Iraq
}

\begin{abstract}
There are several methods that are used to solve the traditional transportation problems whose units of supply, demand quantities, and cost transportation are known exactly. These methods obtain basic solution, and develop it to the best solution through a series of consecutive calculations to obtain the optimal solution. The steps are more complex with fuzzy variables, so this paper presents the disadvantages of solutions of the traditional ways with existence of variables in the fuzzy form.

This paper also presents a comparison between the results that emerged after using different conversion ranking formulas to convert from fuzzy form to crisp form on the same numerical example with a full fuzzy form. The problem has been then converted into a linear programming model, and the BIG-M method to be later used to find the optimal solution that represents the number of units transferred from processing or supply centers to a number of demand centers based on the known cost of transportation.

Achieving the goal of the problem is by finding the lowest total transportation cost, while the comparison is based on that value. The results are presented in a comprehensive table that organizes data and results in a way that facilitates quick and accurate comparison. An amendment to one of the order formats was suggested, because it has different results compared to other formulas. One of the ranking equations is modified, because it has different results compared to other methods.
\end{abstract}

Keywords: Trapezoidal Intuitionistic Fuzzy Numbers, Fuzzy Transportation Problems, Ranking Function, Linear Programming Model.

$$
\begin{aligned}
& \text { دراسة مقارنة لطرق الترتيب في بيانات النقل الضبابية } \\
& \text { سامي كاظم كريم الذبحاوي } \\
& \text { قسم الرياضيات، كلية التربيه، جامعة الكوفه، الكوفه، العراق لاقياقي }
\end{aligned}
$$




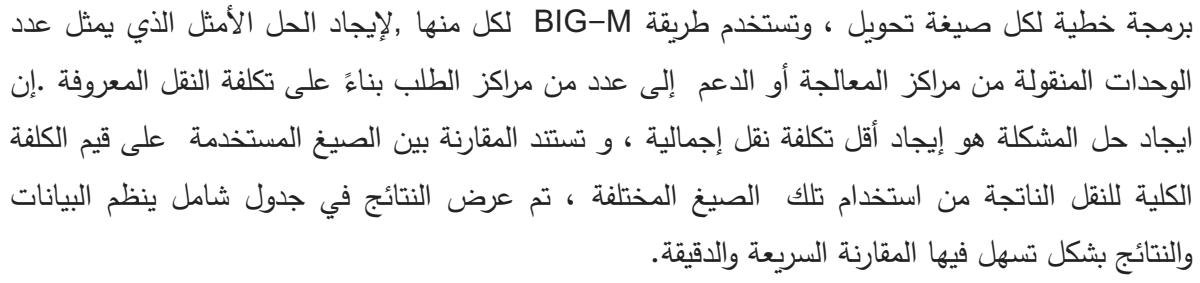

\section{Introduction}

Transportation problem is classified as an important linear programming model which is solving means finding the optimal solution that represents the final optimum value of the total cost of transportation problems. Researchers [1] showed that the first transportation model was presented by Hitchcock. In 1965, the theory of fuzzy set was presented by [2]; whereas, the concepts of uncertainty and fuzzy set were developed by many researchers [3].

In general, the transportation model "classic model" represents the known data in the problem which is the cost of transportation of one unit from supply center to demand center. This model is solved by many different methods to find an optimal solution, such as lower cost LCM, north-west corner NWM, Vogel approximated method VAM, and stepping stone method SSM [4]. All these famous methods looking for an optimal distribution way to transport unites among cells of the model table with lowest total cost value.

Solving the model means finding the number of units $\mathrm{X}_{\mathrm{ij}}$ that are transported from the number (i) of appropriate distribution supply centers to a number ( $\mathrm{j}$ ) of appropriate demand centers, so that the goal is to get the lowest cost of transferred units. These costs are organized in a table which is appropriate to the total number of distribution centers and the number of demand centers as described in Table- 1 [5].

Table 1-Transportation model

\begin{tabular}{|c|c|c|c|c|c|c|c|}
\hline $\mathrm{T}_{1}$ & $\mathrm{D}_{1}$ & $\mathrm{D}_{2}$ & $\mathrm{D}_{3}$ & $\ldots$ &.. & $\mathrm{D}_{\mathrm{n}}$ & \\
\hline \multirow[t]{2}{*}{$\mathrm{S}_{1}$} & $\begin{array}{l}\mathrm{C}_{11} \\
\mathrm{x}_{11}\end{array}$ & $\begin{array}{l}\mathrm{C}_{12} \\
\mathrm{x}_{12}\end{array}$ & $\begin{array}{l}\mathrm{C}_{13} \\
\mathrm{x}_{13}\end{array}$ & $\mathrm{C}_{14}$ & & $\begin{array}{l}\mathrm{C}_{1 \mathrm{n}} \\
\mathrm{x}_{1 \mathrm{n}}\end{array}$ & \\
\hline & $\begin{array}{l}\mathrm{C}_{21} \\
\mathrm{x}_{21}\end{array}$ & $\begin{array}{l}\mathrm{C}_{22} \\
\mathrm{x}_{22} \\
\end{array}$ & $\begin{array}{l}\mathrm{C}_{23} \\
\mathrm{x}_{23}\end{array}$ & $\mathrm{C}_{24}$ & & $\vdots$ & \\
\hline $\mathrm{S}_{\mathrm{i}}$ & $\begin{array}{l}C_{i 1} \\
x_{i 1} \\
\end{array}$ & & & & $\begin{array}{l}C_{i j} \\
x_{i j}\end{array}$ & $\begin{array}{l}C_{\text {in }} \\
\mathrm{x}_{\text {in }}\end{array}$ & \\
\hline $\mathrm{S}_{\mathrm{M}}$ & $\mathrm{C}_{\mathrm{m} 1}$ & $\mathrm{C}_{\mathrm{m} 2}$ & & & & & \\
\hline$D_{i \text { Demand }}$ & $\mathrm{D}_{1}$ & $\mathrm{D}_{2}$ & $\mathrm{D}_{3}$ & $\ldots$ & $\cdots$ & $\mathrm{D}_{\mathrm{n}}$ & $\sum_{1}^{n} D_{j}=\sum_{1}^{m} S_{i}$ \\
\hline
\end{tabular}

where: $\mathrm{x}_{\mathrm{ij}}$ is a number of units which transported from $\left(i^{t h}\right)$ source to $\left(j^{t h}\right)$ demand.

$\mathrm{C}_{\mathrm{ij}}$ is a transportation cost for one unit from $\left(i^{\text {th }}\right)$ source to $\left(j^{\text {th }}\right)$ demand.

$\mathrm{S}_{\mathrm{i}}$ is a number of unit which are available at $\left(i^{\text {th }}\right)$ source.

$\mathrm{D}_{\mathrm{j}}$ is a number of unit which are demanded from $\left(j^{\text {th }}\right)$ destination.

\section{Basic concepts}

In this section, some definitions represent basic information of the proposed comparison [6,7].

Definition 1: A function $\mathfrak{R}: H(\breve{x}) \rightarrow R$ be a ranking function, where $\mathrm{H}(\breve{x})$ is known by a set of fuzzy numbers into real numbers, such that $\mathfrak{R}$ is mapping each fuzzy number (triangular, trapezoidal or pentagon) into real numbers line.

Definition 2: Let $\breve{X}$ subset of universal set of real numbers R then it is said to be fuzzy set number if its membership function $\mu_{\breve{X}}(x)$ mapping domain element $x \in X$ to closed interval

$[0,1]$

Membership function has the following properties.

1 - It is represented by piecewise continues function or discrete points.

2- It holds a convex function property.

3- It is defined by many kinds of parameters as triangular, trapezoidal, pentagonal or octagonal [8]. 
4- If there exists $m_{0} \in X$ such that $\mu_{\check{X}}\left(m_{0}\right)=1$ then $\check{X}$ said to be normal.

The following Figure-1 presents function of trapezoidal Fuzzy numbers

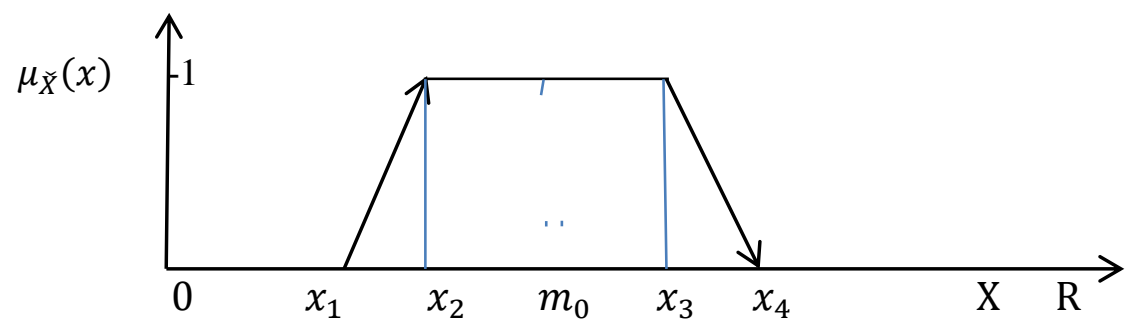

Figure 1-Function of trapezoidal Fuzzy numbers

Definition 3: A fuzzy numbers set $\mathrm{X}$ is said to be triangular fuzzy numbers and expressed by $\left(x_{1}, x_{2}, x_{3}\right)$ where $x_{1}, x_{2}, x_{3}$ are real numbers and its membership function $\mu_{\breve{x}}(x)$ is written as follows [3]:

$$
\mu_{\breve{X}}(x)=\left\{\begin{array}{ccc}
\frac{\alpha-x_{1}}{x_{2}-x_{1}} & \text { if } & x_{1} \leq \alpha<x_{2} \\
1 & \text { if } & \alpha=x_{2} \\
\frac{x_{2}-\alpha}{x_{3}-x_{2}} & \text { if } & x_{2} \leq \alpha<x_{3} \\
0 & & \text { otherwise }
\end{array}\right\}
$$

Definition 4: A fuzzy numbers set $\mathrm{X}$ is said to be trapezoidal fuzzy number and expressed by $\left(x_{1}, x_{2}, x_{3}, x_{4}\right)$ where $x_{1}, x_{2}, x_{3}, x_{4}$ are real numbers and its membership function $\mu_{\breve{X}}(x)$ is formed as follows:

$$
\mu_{\breve{X}}(x)=\left\{\begin{array}{ccc}
\frac{\alpha-x_{1}}{x_{2}-x_{1}} & \text { if } & x_{1} \leq \alpha<x_{2} \\
1 & \text { if } & x_{2} \leq \alpha<x_{3} \\
\frac{x_{4}-\alpha}{x_{4}-x_{3}} & \text { if } & x_{3} \leq \alpha<x_{4} \\
0 & & \text { otherwise }
\end{array}\right\}
$$

Other definitions such as Pentagonal, octagonal, etc. are defined similarly[9].

\section{Mathematical Model and Environment of The fuzzy Transportation}

Transportation problem and its available data include three main parts which follow the model of linear programing. The first part of transportation problems related to existence of the objective function that contains the total cost of transportation which depends on the number of units $\left(x_{i j}\right)$ and $\operatorname{costs} C_{i j}$ that were assigned previously for each cell in the model of transportation problem. The objective function of linear programing is satisfied in terms of the first part that has the following form:

$$
\sum_{i=1}^{m} \sum_{j=1}^{n} C_{i j} * x_{i j}
$$

The second part is satisfied within the form of constraints to the sum of the required units that have been transported. Note that the number of these units cannot be more than number of available supply units[2].

$$
\sum_{j=1}^{n} x_{j} \leq S_{i}
$$


Also, the number of units equipped not less than the number of units required from demand centers.

$$
\sum_{i=1}^{m} x_{j} \geq D_{j}
$$

In general, in transportation model, the number of available units in the supply sources is equal to the number of total demand [6].

$$
\sum_{1}^{m} S_{i}=\sum_{1}^{n} D_{j}
$$

The last requirement of the whole linear programing based on the meaning of non-negativity which is satisfied due to the numbers that are used real and positive units.

$$
x_{i j} \geq 0 ; \quad \text { for all } \mathrm{i}, \mathrm{j} \text {. }
$$

The general mathematical formula for linear programming is represented by the following transportation model [10].

Minimize (Z): $\mathrm{Z}=\sum_{i=1}^{m} \sum_{j=1}^{n} C_{i j} * x_{i j}$

Subject to constraints:

$$
\begin{array}{lc}
\sum_{j=1}^{n} x_{i j} \leq S_{i} ; & \mathrm{i}=1,2,3 \ldots \mathrm{m} \\
\sum_{i=1}^{m} x_{i j} \geq D_{j} ; & \mathrm{j}=1,2,3 \ldots \mathrm{n} \\
\sum_{1}^{m} S_{i}=\sum_{1}^{n} D_{j} ; & \forall \mathrm{i}, \mathrm{j} \\
x_{i j} \geq 0 ; & \forall \mathrm{i}, \mathrm{j}
\end{array}
$$

In many transportation problems the decision maker has no proven and uncertain information about the number of units that are available for transportation from supply centers and the number of requirements for all the following expressions $\left(x_{i j}\right),\left(C_{i j}\right),\left(S_{i}\right),\left(D_{j}\right) \quad$ The fact above is depending on the nature of the topic on which the problem was designed, and can represent these data with triple (triangular) points $\left(C_{i j}{ }^{1}, C_{i j}{ }^{2}, C_{i j}{ }^{3}\right)$ trapezoidal points $\left(C_{i j}{ }^{1}, C_{i j}{ }^{2}, C_{i j}{ }^{3}, C_{i j}{ }^{4}\right.$ ) pentagonal point or more $[6,8]$.

\section{Shortcoming of the Existing Methods}

There are several methods of solution apply algorithms similar to those used in traditional problems, and develop it to include fuzzy data after definition of some operations and properties. Meanwhile, some of shortcoming points arise while applying the algorithms.

1- The algorithms of the famous methods to obtain the basic solution for traditional transportation problem are incompetent when it used to solve a model that contains fuzzy triangular, trapezoidal or pentagonal data [8]. Additionally, some of these problems its data consist of two sets of membership and non-membership, and this resulted in increases the complexity of arithmetical operations [5].

2- The algorithms of the developed methods for solving the fuzzy data need to have many additional calculations in order to obtain the basic solution, and then develop it to reach the optimal solution [11]. 3- Some researchers used the general model of linear programming to solve the fuzzy model by dividing it into problems equal to the number of variables in a single cell. This procedure doubles the number of iterations that used in the algorithm of solution [12].

4- While applying some original algorithms to solve a fuzzy transportation problem because of using subtraction operations, some negative numbers appear in the occupied cells that represent the number of transferred units according to transportation problem model. The negative signal is not realistic and not correspond to the nature of used data[8].

\section{Ranking Functions $(\mathfrak{R})$ :}

In order to avoid the shortcoming that were presented by solving the transportation model which includes data in the form of fuzzy numbers, the ranking function is used for the purpose of converting the data of the problem from fuzzy number to crisp number (R). Thus, ranking function shortens the procedures to reach to the optimal solution. The problem is first converted into a linear programming problem, and then is solved by using a software program (TORA) that characterized by precision and the lowest number of procedures.

To study the results and compare the elements of optimal solution in every format of ranking formulas, the following numerical example in the Table-2 shows a full fuzzy formula data of transportation problem with parameters designed as trapezoidal form. 
Table 2-Data transportation problem represents full fuzzy

\begin{tabular}{|c|c|c|c|c|}
\hline $\mathrm{T}_{2}$ & $\mathrm{D}_{1}$ & $\mathrm{D}_{2}$ & $D_{3}$ & Availability \\
\hline $\mathrm{S}_{1}$ & $\begin{array}{llll}5 & 6 & 8 & 10\end{array}$ & $\begin{array}{llll}7 & 8 & 10 & 12\end{array}$ & $16 \quad 18 \quad 20 \quad 22$ & $\begin{array}{llll}17 & 18 & 20 & 25\end{array}$ \\
\hline $\mathrm{S}_{2}$ & $\begin{array}{llll}37 & 38 & 40 & 42 \\
\end{array}$ & $\begin{array}{llll}28 & 29 & 30 & 32\end{array}$ & 52535557 & 45475055 \\
\hline $\mathrm{S}_{3}$ & $\begin{array}{llll}18 & 19 & 20 & 22 \\
\end{array}$ & $\begin{array}{llll}22 & 23 & 25 & 27\end{array}$ & $\begin{array}{llll}32 & 33 & 35 & 37\end{array}$ & $46 \quad 4650 \quad 55$ \\
\hline Demand & $\begin{array}{llll}8 & 9 & 10 & 12\end{array}$ & $\begin{array}{llll}5 & 6 & 7 & 8\end{array}$ & $\begin{array}{llll}12 & 13 & 14 & 16\end{array}$ & \\
\hline
\end{tabular}

The value of the objective function $\mathrm{Z}$ that obtained from using ranking formula, should be between the objective function of first parameters $x_{1}$ as the lower limit $Z_{L}$ in Table-3 and objective function of the fourth parameters $x_{4}$ as the upper limit $Z_{U}$.

Table 3-The first parameter $x_{1}$ of numerical example

\begin{tabular}{|c|c|c|c|c|}
\hline $\mathrm{T}_{3}$ & $\mathrm{D}_{1}$ & $\mathrm{D}_{2}$ & $\mathrm{D}_{3}$ & Availability \\
\hline $\mathrm{S}_{1}$ & 5 & 7 & 16 & 17 \\
\hline $\mathrm{S}_{2}$ & 37 & 28 & 52 & 45 \\
\hline $\mathrm{S}_{3}$ & 18 & 22 & 32 & 46 \\
\hline Demand & 8 & 5 & 12 & \\
\hline
\end{tabular}

The optimal solution of lower value $Z_{L}$ is:

$x_{13}=12, x_{31}=8, x_{12}=5, x_{32}=0, S x_{14}=45, S x_{15}=38$.

$Z_{L}=16 * 12+18 * 8+7 * 5+22 * 0=371$

The value of objective function (in case upper value $x_{4}$ ) is in the Table- 4

Table 4-The fourth parameter $x_{4}$ of numerical example

\begin{tabular}{|c|c|c|c|c|}
\hline $\mathrm{T}_{4}$ & $\mathrm{D}_{1}$ & $\mathrm{D}_{2}$ & $\mathrm{D}_{3}$ & Availability \\
\hline $\mathrm{S}_{1}$ & 10 & 12 & 22 & 25 \\
\hline $\mathrm{S}_{2}$ & 42 & 32 & 57 & 55 \\
\hline $\mathrm{S}_{3}$ & 22 & 27 & 37 & 55 \\
\hline Demand & 12 & 8 & 16 & \\
\hline
\end{tabular}

Then the optimal solution of upper value $Z_{U}$ is:

$$
x_{11}=1, x_{12}=8, x_{13}=16, x_{31}=11, x_{14}=55, x_{15}=44
$$

The value of the objective function (the upper value) $(16 * 22+1 * 10+8 * 12+22 * 11)=700$.

Therefore, the value of the objective function $\mathrm{Z}$ with any ranking formula must be $371 \leq Z \leq 700$.

The following various ranking formulas are applied on the same numerical example to convert the data from fuzzy to crisp form.

\subsection{The first formula of ranking function:}

Let $(\check{x})$ be a fuzzy number then $\Re(\tilde{x})$ represents the Ropust ranking technique for trapezoidal numbers $[3,13]$.

$\mathfrak{R}(\tilde{x})=\int_{0}^{1} 0.5\left(s_{\alpha}^{l}, s_{\alpha}^{u}\right) d \alpha \quad ; \tilde{x}=\left(x_{1}, x_{2}, x_{3}, x_{4}\right)$

where $\left(s_{\alpha}^{l}, s_{\alpha}^{u}\right)=\left[\left(x_{2}-x_{1}\right) \alpha+x_{1}, x_{4}-\left(x_{4}-x_{3}\right) \alpha\right]$

$$
\text { Then } \Re\left(x_{1}, x_{2}, x_{3}, x_{4}\right)=\int_{0}^{1} o .5\left[\left(x_{2}-x_{1}\right) \alpha+x_{1}, x_{4}-\left(x_{4}-x_{3}\right) \alpha\right] d \alpha
$$

For example $\left.\mathfrak{R}(5,6,8,10)=\int_{0}^{1} o .5[6-5) \alpha+5,10-(10-8) \alpha\right] d \alpha$

$$
=\int_{0}^{1} o .5[\alpha+5+10-2 \alpha] d \alpha
$$

$=0.5[15-1 / 2]=29 / 4=7.25$

The ranking formula is applied on all data of the problem. Then, the results appeared in crisp form, and placed on a similar Table-5. 
Table 5-Application of Rupust ranking formula to convert to crisp form

\begin{tabular}{|c|c|c|c|c|}
\hline $\mathrm{T}_{5}$ & $\mathrm{D}_{1}$ & $\mathrm{D}_{2}$ & $\mathrm{D}_{3}$ & Availability \\
\hline $\mathrm{S}_{1}$ & 7.25 & 9.25 & 19 & 20 \\
\hline $\mathrm{S}_{2}$ & 39.25 & 29.25 & 54.25 & 49.25 \\
\hline $\mathrm{S}_{3}$ & 19.75 & 24.25 & 34.25 & 49.25 \\
\hline Demand & 9.75 & 6.5 & 13.75 & \\
\hline
\end{tabular}

The problem is converted into a linear programming problem with constrains equal to the number of sources, other constraints equals to the number of demand centers and non-negative constrains as shown in the following formula[1].

Minimize (Z) : $Z=\sum_{i=1}^{3} \sum_{j=1}^{3} c_{i j} x_{i j}$

Subject to constraints: $\quad \sum_{j=1}^{3} x_{i j} \leq S_{i}$; such that $\mathrm{i}=1,2,3$

$\sum_{i=1}^{3} x_{i j} \geq D_{j}$; such that $\mathrm{j}=1,2,3$

$$
x_{i j} \geq 0 \quad ; \forall \mathrm{i}, \mathrm{j}
$$

Minimize(Z): $\mathrm{Z}=7.25 x_{11}+9.25 x_{12}+19 x_{13}+39.25 x_{21}+29.75 x_{22}+54.25 x_{23}$

Subject to constraints:

$$
+19.75 x_{31}+24.25 x_{32}+34.25 x_{33}
$$

$x_{11}+x_{12}+x_{13} \leq 20$

$x_{21}+x_{22}+x_{23} \leq 49.25$

$x_{31}+x_{32}+x_{33} \leq 49.25$

where : $\quad x_{i j} \geq 0 ; \forall \mathrm{i}, \mathrm{j}$;

$$
\mathrm{i}, \mathrm{j}=1,2,3
$$

$$
\begin{aligned}
& x_{11}+x_{21}+x_{31} \geq 9.75 \\
& x_{12}+x_{22}+x_{32} \geq 6.5 \\
& x_{13}+x_{23}+x_{33} \geq 13.75
\end{aligned}
$$

The problem is solved after that by software (TORA program).

The optimal solution $x_{12}=6.25, x_{13}=13.75, x_{31}=9.75, x_{32}=0.25$

The value of objective function $Z=9.25 * 6.25+19 * 13.75+19.75 * 9.75+24.25 * 0.25=517.69$.

When the problem solved by Least Cost Method, the results as follow:

\begin{tabular}{|c|c|c|c|c|c|}
\hline $\mathrm{T}_{6}$ & $\mathrm{D}_{1}$ & $\mathrm{D}_{2}$ & $\mathrm{D}_{3}$ & $\mathrm{D}_{4}$ & Availability \\
\hline $\mathrm{S}_{1}$ & $\begin{array}{l}7.25 \\
\underline{\mathbf{0 . 2 5}} \\
\end{array}$ & $\begin{array}{c}9.25 \\
\underline{\mathbf{6}}\end{array}$ & $\begin{array}{c}19 \\
\mathbf{1 3 . 7 5} \\
\end{array}$ & 0 & 20 \\
\hline $\mathrm{S}_{2}$ & 39.25 & $\begin{array}{c}29.25 \\
\mathbf{0 . 5} \\
\end{array}$ & 54.25 & 48.75 & 49.25 \\
\hline $\mathrm{S}_{3}$ & $\begin{array}{c}19.75 \\
9.5\end{array}$ & 24.25 & 34.25 & 39.75 & 49.25 \\
\hline Demand & 9.75 & 6.5 & 13.75 & 88.5 & 118.5 \\
\hline
\end{tabular}

The basic solution is $x_{11}=9.75, x_{12}=6.5, x_{13}=3.75, x_{33}=10$.

The value of objective function $Z=9.25 * 7.25+9.25 * 6.5+19 * 3.75+34.25 * 10=536.93$.

Then the solution improved by a Stepping Stone Method, and the obtained solution shown in the

Table-6

Table 6-The improved solution by the Stepping Stone Method

The optimal solution is $x_{11}=0.25, x_{12}=6.0, x_{13}=13.75, x_{22}=0.5, x_{31}=9.5$

The value of objective function is:

$Z=\sum_{i=1}^{3} \sum_{j=1}^{3} c_{i j} x_{i j}=7.25 * 0.25+9.25 * 6.0+19 * 13.75+29.25 * 0.5+19.75 * 9.5=520.81$.

It is obvious from the results of the total cost Z by using the TORA Program is lower than the cost produced by using the Least Cost Method and then Stepping Stone Method.

\subsection{The second formula of ranking function:}

This formula is applied on the original problem.[12]

$\Re(\check{x})$ where $(\check{x})=\left(x_{1}, x_{2}, x_{3}, x_{4}\right)$

where: $\Re(\check{x})=\left(x_{1}, x_{2}, x_{3}, x_{4}\right)=\frac{1}{2}\left(x_{1}+x_{2}\right)+\frac{1}{4}\left(x_{4}-x_{3}\right)=\frac{\left(2 x_{1}+2 x_{2}+x_{4}-x_{3}\right)}{4}$

In another form of the same formula:

$(\Re \check{x})=\Re(m, n, \propto, \beta)=\left(4 x_{1}+3 x_{2}+2 x_{3}+x_{4}\right) / 4$ 


$$
\begin{gathered}
\text { where } x_{1}=\mathrm{m}-\propto, x_{2}=\propto, x_{3}=n-m, x_{4}=\beta \\
\Re(\check{x})=\mathfrak{R}\left(x_{1}, x_{2}, x_{3} x_{4}\right)=\frac{4\left(x_{1}-x_{3}\right)+3\left(x_{3}\right)+2\left(x_{2}-x_{1}\right)+x_{4}}{4}
\end{gathered}
$$

By applying the same trapezoidal fuzzy example:

$\Re(5,6,8,10)=\frac{4(5-8)+3(8)+2(6-5)+10}{4}=\frac{-12+24+12}{4}=\frac{24}{4}=6$

Likewise, all data in table 5 is converted by using the current ranking formula. The results are then converted into a linear programming model and by using TORA Program to obtain the optimal solution as shown in the following Table-7.

\begin{tabular}{|c|c|c|c|c|c|}
\hline $\mathrm{T}_{7}$ & $\mathrm{D}_{1}$ & $\mathrm{D}_{2}$ & $\mathrm{D}_{3}$ & dummy & Availability \\
\hline $\mathrm{S}_{1}$ & $\begin{array}{l}6 \\
9\end{array}$ & $\begin{array}{c}8 \\
5.75\end{array}$ & $\begin{array}{c}17.5 \\
4\end{array}$ & 0 & 18.75 \\
\hline $\mathrm{S}_{2}$ & 38 & 29 & $\begin{array}{c}26 \\
9\end{array}$ & 0 & 47.25 \\
\hline $\mathrm{S}_{3}$ & 19 & 23 & 33 & 0 & 47.25 \\
\hline Demand & 9 & 5.75 & 13 & 85.5 & 113.25 \\
\hline
\end{tabular}

Table 7-Data and solution by using the second ranking formula

$x_{11}=9, x_{12}=5.75, x_{13}=4, x_{23}=9$

The value of objective function:

$Z=\sum_{i=1}^{3} \sum_{j=1}^{3} c_{i j} x_{i j}=6 * 9+8 * 5.75+17.5 * 4+26 * 9=444.5$.

\subsection{The third formula of ranking function:}

$\Re(\check{x})$ where $\tilde{x}=\left(x_{1}, x_{2}, x_{3}, x_{4}\right)[9,14]$

$$
\mathfrak{R}(\check{x})=\mathfrak{R}\left(x_{1}, x_{2}, x_{3}, x_{4}\right)=\left(x_{1}+x_{2}+x_{3}+x_{4}\right) / 4
$$

For example $\Re(\check{x})=(5,6,8,10)=(5+6+8+10) / 4=7.25$

By applying the same steps as in the second model of the ranking function, the following results are obtained in $\mathrm{T}_{8}$

Table 8-Data and solution by using the third ranking formula.

\begin{tabular}{|c|c|c|c|c|c|}
\hline $\mathrm{T}_{8}$ & $\mathrm{D}_{1}$ & $\mathrm{D}_{2}$ & $\mathrm{D}_{3}$ & Dummy & Availability \\
\hline $\mathrm{S}_{1}$ & 7.25 & $\begin{array}{c}9.25 \\
\mathbf{6 . 2 5}\end{array}$ & $\begin{array}{c}19 \\
\mathbf{1 3 . 7 5}\end{array}$ & 0 & 20 \\
\hline \multirow{2}{*}{$\mathrm{S}_{2}$} & 39.25 & 29.75 & 54.25 & $\begin{array}{c}0 \\
49.25\end{array}$ & 49.25 \\
\hline \multirow{2}{*}{$\mathrm{S}_{3}$} & $\begin{array}{c}19.75 \\
\mathbf{9 . 7 5}\end{array}$ & $\begin{array}{c}24.25 \\
\mathbf{0 . 2 5}\end{array}$ & 34.25 & $\begin{array}{c}0 \\
39.25\end{array}$ & 49.25 \\
\hline Demand & 9.75 & 6.5 & 13.75 & 88.5 & 118.5 \\
\hline
\end{tabular}

$x_{13}=13.75, x_{31}=9.75, \quad x_{12}=6.25, x_{32}=0.25$

The value of objective function is

$Z=\sum_{i=1}^{3} \sum_{j=1}^{3} c_{i j} x_{i j}=6.25 * 9.25+19 * 13.75+19.75 * 9.75+0.25 * 24.25=517.69$

\subsection{The fourth formula of ranking function:}

$\Re(\check{x})$ where $(\check{x})=\left(x_{1}, x_{2}, x_{3}, x_{4}\right)[9]$.

$\Re(\check{x})=\Re\left(x_{1}, x_{2}, x_{3}, x_{4}\right)=\frac{\left(x_{1}+2 x_{2}+2 x_{3}+x_{4}\right)}{6}$

For example $\mathfrak{R}(\check{x})=(5,6,8,10)=(5+2 * 6+8 * 2+10) / 6=7.20$

By applying the same steps as in the previous models of the ranking function.

The results of optimal solutions are bolded in Table- 9 . 
Table 9-Data and solution by using the fourth ranking formula

\begin{tabular}{|c|c|c|c|c|c|}
\hline $\mathrm{T}_{9}$ & $\mathrm{D}_{1}$ & $\mathrm{D}_{2}$ & $\mathrm{D}_{3}$ & dummy & Availability \\
\hline $\mathrm{S}_{1}$ & 7.67 & $\begin{array}{c}9.67 \\
\mathbf{6}\end{array}$ & $\begin{array}{c}19 \\
\mathbf{1 3 . 7}\end{array}$ & $\mathbf{0}$ & 19.7 \\
\hline $\mathrm{S}_{2}$ & 39.17 & 29.67 & 54.17 & $\begin{array}{c}0 \\
\mathbf{4 9}\end{array}$ & 49 \\
\hline $\mathrm{S}_{3}$ & $\begin{array}{c}19.67 \\
\mathbf{9 . 7}\end{array}$ & $\begin{array}{c}24.17 \\
\mathbf{0 . 5}\end{array}$ & 34.17 & $\begin{array}{c}0 \\
\mathbf{3 8 . 6}\end{array}$ & 48.8 \\
\hline Demand & 9.67 & 6.5 & 13.67 & 87.6 & 117.5 \\
\hline
\end{tabular}

$x_{12}=6, x_{13}=13.75, x_{31}=9.7, x_{32}=0.5$

The value of objective function:

$Z=\sum_{i=1}^{3} \sum_{j=1}^{3} c_{i j} x_{i j}=9.2 * 6+19 * 13.7+19.7 * 9.7+0.5 * 24.2=518.69$

5.5. The fifth formula of ranking function [15]:

$\Re(\check{x})=\sqrt{\varphi_{1}(\check{x})+\varphi_{2}(\check{x})}$

where: $(\check{x})=\left(x_{1}, x_{2}, x_{3}, x_{4}\right)$ and $\varphi_{1}(\check{x})=1 / 3 \sqrt{\left(\left(x_{1}+x_{2}+x_{3}+x_{4}\right)-\frac{x_{3} x_{4}-x_{1} x_{2}}{\left(x_{4}+x_{3}\right)-\left(x_{1}+x_{2}\right.}\right)}$

$\varphi_{2}(\check{x})=1 / 3 \sqrt{\left(1+\frac{x_{3}-x_{2}}{\left(x_{4}+x_{3}\right)-\left(x_{1}+x_{2}\right.}\right)}$

Similarly, the data is converted by using the fifth ranking formula in the Table-10

Table 10-data and solution by using the fifth ranking formula

\begin{tabular}{|c|c|c|c|c|c|}
\hline $\mathrm{T}_{10}$ & $\mathrm{D}_{1}$ & $\mathrm{D}_{2}$ & $\mathrm{D}_{3}$ & dummy & Availability \\
\hline $\mathrm{S}_{1}$ & 2.77 & $\begin{array}{c}3.117 \\
\mathbf{1 . 9 1}\end{array}$ & 4.406 & 0 & 4.54 \\
\hline \multirow{2}{*}{$\mathrm{S}_{2}$} & 6.3 & 5.49 & 7.39 & $\begin{array}{c}0 \\
\mathbf{7 . 0 6}\end{array}$ & 7.06 \\
\hline \multirow{2}{*}{$\mathrm{S}_{3}$} & 4.49 & 4.97 & 5.89 & $\begin{array}{c}0 \\
\mathbf{2 . 0 9}\end{array}$ & 7.06 \\
\hline Demand & 3.11 & 2.63 & 3.77 & 9.15 & 18.66 \\
\hline
\end{tabular}

When the current ranking formula is applied ranking function 13 , the results are quite different from the results obtained from using other formulas in this paper. The reason for that is the incompatibility with the transport model data.

\subsection{The sixth formula of ranking function:}

$$
\Re(\check{x})=\frac{2 x_{1}+7 x_{2}+7 x_{3}+2 x_{4}}{18} *\left(\frac{7 w}{18}\right)[16]
$$

where, $(\widetilde{\boldsymbol{x}})=\left(x_{1}, x_{2}, x_{3}, x_{4}\right)$, let $\mathrm{w}=1$, ( normalize fuzzy).

For example: $\mathfrak{R}(32,3 \overline{3,35}, 37)=\frac{2 * 32+7 * 33+7 * 35+2 * 37}{18} *(7 / 18)=13.27$

By applying the same steps as in the previous models of the ranking function, the crisp results are placed in Table-11 The optimal solutions is bolded in same table.

Table 11-Data and solution by using the sixth ranking formula

\begin{tabular}{|c|c|c|c|c|c|}
\hline $\mathrm{T}_{11}$ & $\mathrm{D}_{1}$ & $\mathrm{D}_{2}$ & $\mathrm{D}_{3}$ & dummy & Availability \\
\hline$S_{1}$ & 2.76 & $\begin{array}{l}3.54 \\
2.27\end{array}$ & $\begin{array}{l}7.38 \\
\mathbf{5 . 2 9}\end{array}$ & 0 & 7.56 \\
\hline $\mathrm{S}_{2}$ & 5.21 & 11.51 & 21.04 & 18.99 & 18.99 \\
\hline $\mathrm{S}_{3}$ & $\begin{array}{l}7.63 \\
\mathbf{3 . 7 4}\end{array}$ & $\begin{array}{l}9.38 \\
\mathbf{0 . 2 6}\end{array}$ & 13.27 & $\begin{array}{c}0 \\
14.88\end{array}$ & 18.88 \\
\hline Demand & 3.74 & 2.53 & 5.29 & 33.87 & 45.43 \\
\hline
\end{tabular}

$x_{12}=2.27, x_{13}=5.29, x_{31}=3.74, x_{32}=0.26$

The value of the objective function is: 
$Z=\sum_{1}^{3} \sum_{1}^{3}\left[C_{I J} x_{i j}\right]=3.54 * 2.27+7.38 * 5.29+7.63 * 3.74+9.38 * 0.26=78.051$

Note that the current result of the total transportation cost $Z=78.05$ is quite different from the other results of the previous formulas, and it is out of the limits. The reason for that difference is finding the center of the trapezoidal shape that has been segmented in to triangles and then finding the center of the resulting triangles as shown in the Figure-2.

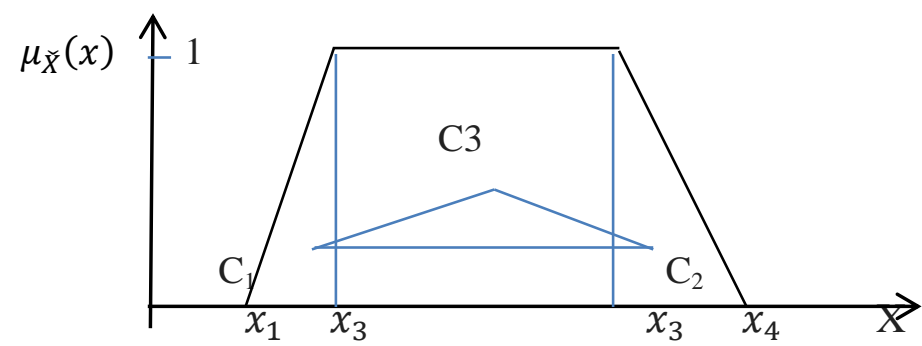

Figure 2-Centroid Ranking Method

Therefore, the ranking formula can be adjusted by removing the weight ratio (7/18) of the trapezoidal variables.

The adjusted form of the formula is: $\Re(\check{x})=\frac{2 x_{1}+7 x_{2}+7 x_{3}+2 x_{4}}{18}$

The obtained results of the adjusted formula is $Z=516.31$ by applying the data of Table- 12 .

Table 12-Data and solution by using the adjusted formula of ranking

\begin{tabular}{|c|c|c|c|c|c|}
\hline$T_{12}$ & $\mathrm{D}_{1}$ & $\mathrm{D}_{2}$ & $\mathrm{D}_{3}$ & Dummy & Availability \\
\hline $\mathrm{S}_{1}$ & 7.11 & $\begin{array}{l}9.11 \\
\mathbf{5 . 8 3}\end{array}$ & $\begin{array}{c}19 \\
13.61\end{array}$ & 0 & 19.44 \\
\hline $\mathrm{S}_{2}$ & 39.11 & 29.61 & 54.11 & 0 & 48.83 \\
\hline $\mathrm{S}_{3}$ & $\begin{array}{c}19.61 \\
\mathbf{9 . 6 1}\end{array}$ & $\begin{array}{c}24.11 \\
\mathbf{0 . 6 7}\end{array}$ & 34.11 & $\begin{array}{c}0 \\
38.28\end{array}$ & 48.56 \\
\hline Demand & 9.61 & 6.5 & 13.61 & 87.11 & 116.83 \\
\hline
\end{tabular}

Consequently, the obtained results are similar to the results obtained by applying other ranking equations, as shown in the column $7-\left[16^{*}\right]$ of Table- 13 .

\section{6- Results}

The aim of this study is to compare between various ranking formulas to obtain the optimal solution in order find the minimum value of total cost of transportation. The data and results that placed in the table for comparison and analysis, columns A-D are trapezoidal fuzzy numbers for numerical example, columns E-K represent the results of applying ranking formulas, column $\mathrm{L}$ represents result of LCM and column M represents result of SSM as shown in Table-13

Tabel 13-resultes of various ranking formulas

\begin{tabular}{|c|c|c|c|c|c|c|c|c|c|c|c|c|c|}
\hline $\begin{array}{c}\mathbf{T} \\
\mathbf{1 3}\end{array}$ & $\mathrm{A}$ & $\mathrm{B}$ & $\mathrm{C}$ & $\mathrm{D}$ & $\mathrm{E}$ & $\mathrm{F}$ & $\mathrm{G}$ & $\mathrm{H}$ & $\mathrm{I}$ & $\mathrm{J}$ & $\mathrm{K}$ & $\mathrm{L}$ & $\mathrm{M}$ \\
\hline & $\mathrm{X}_{1}$ & $\mathrm{X}_{2}$ & $\mathrm{X}_{3}$ & $\mathrm{X}_{4}$ & $1-[3]$ & $2-[12]$ & $3-[14]$ & $4-[7]$ & $5-[15]$ & $6-[16]$ & $7-[16 *]$ & $\mathrm{LCM}$ & $\mathrm{SSM}$ \\
\hline $\mathrm{C}_{11}$ & 5 & 6 & 8 & 10 & 7.25 & 6 & 7.25 & 7.1667 & 2.777 & 2.76543 & 7.11111 & 7.25 & 7.25 \\
\hline $\mathrm{C}_{12}$ & 7 & 8 & 10 & 12 & 9.25 & 8 & 9.25 & 9.1667 & 3.117 & 3.54321 & 9.11111 & 9.25 & 9.25 \\
\hline $\mathrm{C}_{13}$ & 16 & 18 & 20 & 22 & 19 & 17.5 & 19 & 19 & 4.406 & 7.38889 & 19 & 19 & 19 \\
\hline $\mathrm{C}_{21}$ & 37 & 38 & 40 & 42 & 39.25 & 38 & 39.25 & 39.167 & 6.302 & 15.2099 & 39.1111 & 39.25 & 39.25 \\
\hline $\mathrm{C}_{22}$ & 28 & 29 & 30 & 32 & 29.75 & 29 & 29.75 & 29.667 & 5.495 & 11.5154 & 29.6111 & 29.75 & 29.75 \\
\hline $\mathrm{C}_{23}$ & 52 & 53 & 55 & 57 & 54.25 & 53 & 54.25 & 54.167 & 7.397 & 21.0432 & 54.1111 & 54.25 & 54.25 \\
\hline
\end{tabular}




\begin{tabular}{|c|c|c|c|c|c|c|c|c|c|c|c|c|c|}
\hline $\mathrm{C}_{31}$ & 18 & 19 & 20 & 22 & 19.75 & 19 & 19.75 & 19.667 & 4.494 & 7.62654 & 19.6111 & 19.75 & 19.75 \\
\hline $\mathrm{C}_{32}$ & 22 & 23 & 25 & 27 & 24.25 & 23 & 24.25 & 24.167 & 4.971 & 9.37654 & 24.1111 & 24.25 & 24.25 \\
\hline $\mathrm{C}_{33}$ & 32 & 33 & 35 & 37 & 34.25 & 33 & 34.25 & 34.167 & 5.892 & 13.2654 & 34.1111 & 34.25 & 34.25 \\
\hline $\mathrm{S}_{1}$ & 17 & 18 & 20 & 25 & 20 & 18.75 & 20 & 19.667 & 4.539 & 7.56173 & 19.4444 & 20 & 20 \\
\hline $\mathrm{S}_{2}$ & 45 & 47 & 50 & 55 & 49.25 & 47.25 & 49.25 & 49 & 7.057 & 18.9907 & 48.8333 & 49.25 & 49.25 \\
\hline $\mathrm{S}_{3}$ & 46 & 46 & 50 & 55 & 49.25 & 47.25 & 49.25 & 48.833 & 7.06 & 18.8827 & 48.5556 & 49.25 & 49.25 \\
\hline $\mathrm{D}_{1}$ & 8 & 9 & 10 & 12 & 9.75 & 9 & 9.75 & 9.6667 & 3.194 & 3.73765 & 9.61111 & 9.75 & 9.75 \\
\hline $\mathrm{D}_{2}$ & 5 & 6 & 7 & 8 & 6.5 & 5.75 & 6.5 & 6.5 & 2.63 & 2.52778 & 6.5 & 6.5 & 6.5 \\
\hline $\mathrm{D}_{3}$ & 12 & 13 & 14 & 16 & 13.75 & 13 & 13.75 & 13.667 & 3.768 & 5.29321 & 13.6111 & 13.75 & 13.75 \\
\hline $\mathrm{Z}$ min & \multicolumn{1}{|c|}{ by TORA PO. } & 517.69 & 444.5 & 517.69 & 517.04 & 40.64 & 78.051 & 516.31 & 536.9 & 520.8 \\
\hline
\end{tabular}

\section{Discussion and Conclutions}

After studying the results and comparing them, the following are obtained:

7.1. Using varies ranking formulas shortens the steps and requirements of the solutions, as the model can be solved by using one parameter instead of using three or four parameters for fuzzy data

7.2. Solving the original problem of fuzzy numbers, the minimum numbers of all data. $x_{i j}, C_{i j}, S_{i j}, D_{i j}$ are taking to form a problem its result represent the lower limit $\mathrm{Z}_{\mathrm{L}}=371$ units of cost, while the maximum numbers of the data are also taking to form a problem its solving represent the upper limit $\mathrm{Z}_{\mathrm{U}}=700$ units Table -4 , Table -5 .

7.3. The lowest value has been achieved when applying the ranking function (10) of column $F$ in the table of results Table-13 The reason for that is the ranking function gives greater weight to the first and second elements of fuzzy number $\left(x_{1}, x_{2}\right)$ and less weight for other parameters $\left(x_{4}, x_{3}\right)$.

7.4. Data and results that are obtained by applying the fifth formula are not accepted depending on the nature of the model of transportation as they are out of the limits.

7.5. The value of the ranking function is dependent on the weight given to every element of the fuzzy numbers. In order to achieve the realism in transportation problem, the formula (14)

is adjusted as formula(15).

\section{References}

1. Sharma, G., Abbas, S.H. and Gupta, V.K. June. 2012. Solving Transportation Problem with the help of Integer Programming Problem. IOSR Journal of Engineering, 2(6): 1274-1277.

2. Zadeh, L. A.1965. Fuzzy sets, Information and Control.

3. Shugani, P., Abbas, S.H. and Gupta, V. 2012. Unbalanced fuzzy transportation problem with roubast technique. Asian Journal of Current Engineering and Maths.

4. Kaur, A. and Kumar, A. 2011. Anew method for solving fuzzy transportation, problems using ranking function, Applied mathematical modeling, 35: 5652-5661.

5. Kumar, P.S. and Hussain, R. j. 2015. A method for solving unbalanced intuitionistic. fuzzy transportation problems.1310-4926, 21(3).

6. Maheswari, p. and Ganesan, K. 2018 , IOP Conf. Series: Journal of Physics: Conf. Series 1000, , 012014. Solving fully fuzzy transportation problem using pentagonal fuzzy numbers, National Conference on Mathematical Techniques and its applications (NCMTA 18) IOP Publishing,

7. Vidhya, V. and Ganesan K., Efficient solution of a multi objective fuzzy transportation problem, IOP Conf. Series: Journal of Physics: Conference Series 1000 012132, 2018.

8. Malini, P. and Ananthanarayanan, M. 2016. Solving fuzzy Transportation problem using ranking of octagonal fuzzy numbers, International Journal of Pure and Applied Mathematics, 110(2): 275282.

9. Sathish, S. and Ganesan, K. 2011. A simple approach to fuzzy critical path analysis in project networks, International Journal of Scientific \& Engineering Research, 2(12). 
10. Sharma, V., Abbas, S.H. and Gaurav, V.K. 2012. Solving transportation problem with the various method of linear programming problem, Asian Journal of Current Engineering and Maths.

11. Acharya, D., Bsua M. and Das, A. 2013. Modified Method for Fixed Charge Transportation Problem, International Journal of Engineering Inventions, 3(1): 67-71.

12. Kumar, A. and Kaur, A. 2011. Application of linear programming for solving fuzzy transportation problems, J. Appl. Math. \& Informatics, 29.

13. Kalaiarasi, K., Sindhu, S. and Arunadevi, M. 2014. Optimization of trapezoidal balanced transportation problem using zero-suffix and Robust Ranking Methodology with fuzzy demand and fuzzy supply models, International Journal of Computing Science and Information Technology.

14. Amoorthy, S.S. and Maheswari, S.S. 2013. A Method for Solving Fuzzy Transportation Problem (FTP) using Fuzzy Russell's Method. Intelligent Systems and Applications.

15. Purushothkumar, M.K. and Ananathanarayanan, M. 2017. Fuzzy Transportation problem of Trapezoidal Fuzzy numbers with New Ranking Technique, IOSR Journal of Mathematics, 13(6): 06-12.

16. Saini, R.K., Sangal, A. and Pakash, O. 2015. Unblnced Transportation Problems in Fuzzy Environment using Centroid Ranking Technique. International Journal of Computing Application (0975-8887) 110(11). 